\title{
Aquilo que a dobra guarda
}

Ángela Maria Cuartas Villalobos ${ }^{1}$

Geysiane Aparecida de Andrade ${ }^{2}$

Juliana Maffeis ${ }^{3}$

Pensar o processo criativo como um espaço de convívio da potência em direção ao ato e a potência-de-não amplia o estudo da criação artística em suas especificidades, para, entre diferentes possibilidades, lidar com o olhar vertical de outras práticas ou áreas de conhecimento, sob o qual ainda está a área da escrita criativa no contexto acadêmico. A negação desse espaço resulta em uma busca pela totalidade que tende a aproximar a escrita literária mais de um regime autoritário interno do que de um exercício criativo fértil. É preciso questionar a ideia de que a pausa, a quietude, o não saber, o não fazer e a fratura são estados que impedem a criação, e assumir que se cria também (e intrinsecamente) em estado de repouso e ausência de controle. É um princípio da vida: o abandono próprio do sono é necessário para manter a sanidade. Parafraseando Joyce Carol Oates ${ }^{4}$ : os sonhos são viagens temporárias à loucura que nos mantêm afastados da loucura verdadeira. Mas até essa obviedade nos foi roubada pela urgência do rendimento produtivo, que sempre é para alguém ou algo mais: poucas vezes serve a um objetivo que esteja em ressonância com o próprio espírito. É necessário se armar de valor e de um facão para andar pelo mundo reivindicando o direito a não saber e a não querer seguir o ritmo sempre acelerado da produtividade. Talvez não exista nenhuma área, nenhum âmbito social que escape a essa violência.

O percurso que escolhi para mostrar o andamento da criação se assemelha à montagem literária, como no método de trabalho encontrado em Passagens, de Benjamin, obra inacabada que olha a cidade de Paris no século XIX, para o qual o autor coletou material de 1927 a 1929, e depois de 1934 a 1940. A ordem das notas não corresponde à cronologia de sua gênese, pois, aparentemente, Benjamin sempre abria um novo arquivo quando, em seus estudos, surgia um novo tema que ele julgava importante. Dessa forma, o filósofo constrói 4.500 passagens de suas leituras sobre a cidade para relevar a montagem como seu método de trabalho e conta: "Método deste trabalho: montagem literária. Não tenho nada a dizer. Somente a mostrar. Não me apropriarei de formulações espirituosas, não surrupiarei coisas valiosas. Porém, os farrapos, os resíduos: estes não quero descrever e sim exibir" ${ }^{5}$. Mapear um processo criativo é como cartografar um labirinto. Acredito que o movimento corresponde ao ruído da fragmentação de uma imagem contínua, como um mapa tradicional

\footnotetext{
1 Doutoranda em Escrita Criativa, Pontifícia Universidade Católica do Rio Grande do Sul (PUCRS). Contato: cuartas.angela@gmail.com

2 Doutoranda em Escrita Criativa, Pontifícia Universidade Católica do Rio Grande do Sul (PUCRS). Contato: geysiaandrade@gmail.com

3 Doutoranda em Escrita Criativa, Pontifícia Universidade Católica do Rio Grande do Sul (PUCRS). Contato: maffeisjuliana@gmail.com

${ }^{4}$ OAtes, J.C. Running and Writing. In: OATES, Joyce Carol. The Faith of a Writer: Life, Craft, Art. London: PerfectBound, 2003, p. 36.

${ }^{5}$ BenJAmin, W. Passagens. Imprensa Oficial/Ed. UFMG, 2006, p. 881.
} 
totalizante e seguro que se rompe na ideia de desorientação ao separar as regiões em pequenos textos, como ilhas rodeadas de uma falsa noção de proximidade, distância ou fronteiras.

O sol tem diminuído o percurso diário. Chega apenas até a esquina do prédio à direita e entra pela fresta displicente da cortina, aquecendo o piso laminado. Os dias vão ficando menores. Acostumada à casa, percorro a sala-quarto, meu espaço criativo. Preparo a mesa: limpo o computador, pego lápis, caneta, o livro e o caderninho. Passo um café, me sirvo de uma xícara com o líquido a um dedo da borda e uma colher de açúcar, deixo do lado. Escolho a posição mais cômoda, sentada, coluna ereta, ponho uma almofada nas costas, estico as pernas e pronto. Coloco os óculos, navego pela rede, abro uma página, que me leva a outra, que me leva a outra, que me leva a outra... Paro, preciso ir ao banheiro. Pego as pastas e mexo nos papéis, releio antigas anotações e textos dos velhos caderninhos. Tiro uma folha em branco e volto para a cadeira. Braços dobrados, cotovelos sobre a mesa e as mãos seguram o queixo. Abro um livro para aquecer e pegar o ritmo da leitura. Retiro a tampa da caneta para começar a escrever. Aliás, melhor escrever a lápis, sempre tive medo da tinta definitiva que marca o papel e depois não tem como consertar, a não ser borrar ainda mais.

O campo de forças em tensão próprio do processo da escrita também é descrito por Mario Levrero ${ }^{6}$ quando relata o nascimento de suas histórias. Ele conta que no início há um incômodo. Alguma coisa, uma série de palavras, uma imagem ou uma atmosfera o envolve e fica grudado nele, perturbando-o, como quando o ambiente ou a visão de um sonho o acompanham o dia inteiro até se dissipar. Só que às vezes não se dissipam e ele entende isso como um sinal de que há algo ali que precisa ser recriado. Ele examina aquilo que o perturba até distinguirlhe os detalhes, o contexto, a história. E esse examinar, diz ele, não é outra coisa que prestar atenção, permitir que viva sua vida. Segundo ele, isto permite que a "mensagem" da imagem ou daquilo que está perturbando chegue do inconsciente à consciência. Ao falar da "alquimia" da escrita (ele prefere essa expressão, em vez da ideia dos mecanismos literários), Levrero também compara o processo da escrita com a digestão: existe toda uma dimensão oculta, inclusive para o escritor, de procedimentos secretos na criação literária. Essa relação com a matéria da escrita lembra uma imagem usada por Agamben quando propõe repensar o paradigma teológico da criação a partir do nada. No ensaio Vórtices ${ }^{7}$ ele repensa o ato criativo retomando a imagem benjaminiana da origem como uma espiral. Agamben compara a obra de arte, o sujeito e o nome com as formas autônomas, fechadas em si mesmas e regidas por leis próprias que surgem em um rio quando o curso da água encontra alguma resistência a seu andamento livre. Quando a água se estagna, em determinado momento se forma um vórtice que permite que o fluxo siga seu curso.

É preciso admitir a impossibilidade de se determinar o primeiro instante em que se desencadeou o processo de criação ou qual foi o movimento derradeiro que fez o artista terminar sua obra. Tal operação, para Cecília Almeida Salles, é praticamente impossível, pois a obra está sempre em estado de provável mutação e toda criação é, assim, observada no estado de contínua metamorfose: "um percurso feito de formas de caráter precário, porque hipotético" ${ }^{\prime}$. Nesse entendimento, o processo criativo produz conexões entre seus elementos e movimenta linhas de maneira que, a todo momento, novos mapas podem ser criados e cartografados.

\footnotetext{
${ }^{6}$ LeVrero, M. Entrevista imaginária com Mario Levrero. In: LEVRERO, Mario. Deixa comigo. Tradução de Joca Reiners Terron. Rio de Janeiro: Rocco, 2013, p. 119-145.

${ }^{7}$ Agamben, G. O fogo e o relato. Ensaios sobre criação, escrita, arte e livros. Trad. Andrea Santurbano e Patricia Peterle. São Paulo: Boitempo Editorial, 2018, p. 83

${ }^{8}$ SALLES, C. Gesto inacabado. Processo de criação artística. São Paulo, Fapesp. Editora: Annablume, 2008, p. 26.
} 
Encontrei um método para mapear minha narrativa colecionando imagens recortadas em uma caixa de sapatos. Talvez minha recorrente fuga das palavras tenha me levado a escrever de outra forma. Quando amigos me visitavam, era uma oportunidade de apresentar meus personagens sem cabeça, passarinhos com asas de avião e girafas com meia dúzia de pernas humanas. Livre das palavras, me sinto à vontade para explorar meu pátio e brincar com a minha verdade.

Sem perceber, o raio de sol caminha ligeiramente e já quase alcança a porta de entrada, iluminando a folha em branco. Lembro que não reguei as plantas e também sobrou a louça do café. A música do vizinho aumenta. Melhor fazer uma caminhada. Alguns autores falam que para escrever é preciso solidão ou uma desordem, um caos interior. Então, talvez eu não tenha vivido nem sofrido o suficiente para conseguir transpor tudo para o poema. Talvez esteja esperando a tal inspiração, e a ansiedade impeça que ela venha. Talvez não pratique o suficiente, preciso ler e aprender mais. Talvez eu esteja com a Síndrome de Bartleby da qual fala Vila-Matas ${ }^{9}$ : uma pulsão negativa e atração pelo nada que me faz renunciar à escrita e optar pela literatura do não. O que está à minha frente é uma superfície intacta e cheia de sol que se revela paralisada, muda e, ao mesmo tempo, calma, fresca, sem desespero. A página em branco é uma promessa de vida ou uma vida inteira que espera ser passada a limpo. É um símbolo angustiante e, ao mesmo tempo, fecundo de pura possibilidade. Contemplo não a obra escrita, mas sim a potência da escritura.

O abandono do trabalho, a incomunicabilidade da obra fora do contexto de criação e o risco de perder o esforço do trabalho sobre si em um jogo interno - um exercício narcisista -, que não diz nada nem leva a uma forma-de-vida, seriam, para Agamben, alguns dos riscos de experimentar o trabalho sobre si em aliança com o ato criativo, quando não se leva em consideração que esse ato é uma tensão que não se resolve, quer dizer, quando não se assume que o poder de criar não anula o de não criar. O que Agamben chama de forma-de-vida é "o ponto em que o trabalho numa obra e o trabalho sobre si coincidem perfeitamente" ${ }^{10}$. Segundo ele, a vida poética seria aquela que encontra paz na contemplação da inoperosidade da linguagem, da visão ou do corpo, que se contempla a si também como pura potência. É importante fazer a distinção: as experiências de leitura e escrita podem ser experiências de solidão, mas não de isolamento. Elas são justamente esse ponto de encontro entre duas forças: aquela que nos leva para dentro de nós, ou das nossas trincheiras, e aquela que nos leva de encontro ao mundo. Mas é um encontro da dimensão interna dos sentidos com a matéria-prima do mundo. Os sentidos que leem e escrevem o mundo não são os da vida ordinária, são raízes deles, mais profundas, mais internas e indiferenciadas, que crescem ramificando-se para fora da pele e não se encontram com os contornos fixos do mundo, nem acompanham o percurso dos limites das coisas supostamente já dadas, eles criam novos limites e novas vias de conexão com a matéria.

Imagino Antoine Compagnon ${ }^{11}$ bem velhinho retornando à infância pelo prazer do recorte. Todas as manhãs, ele recebe o jornal, que recorta linha por linha, em longas tiras de papel que cola umas às outras e enrola como uma fita de máquina de escrever. Sentado numa poltrona, ele confessa: não lerei mais, não escreverei mais, não saberei mais nem ler nem escrever, mas estarei ligado ainda ao papel, à tesoura e à cola.

\footnotetext{
${ }^{9}$ Vila-Matas, E. Bartleby e companhia. Trad. Maria Carolina de Araújo e Josely Vianna Baptista. São Paulo: Cosac Naify, 2004.

${ }^{10}$ AGAMBEN, op. cit. p., 166.

${ }^{11}$ Compagnon, A. O trabalho da citação. Minas Gerais: UFMG, 2007, p. 11.
} 
Ao seu lado, me sinto uma velha cheirando cola enquanto tento cortar os pulsos com uma tesoura sem ponta. Encontrar uma boa imagem, para quem se delicia com as possibilidades da visualidade, é uma barbada. O problema começa quando tenho a intenção de tirá-la de seu contexto para encaixar em outra realidade, inventada, minha. Duvido da essência de tudo que vejo. Passo a questionar o que é um texto, o que é uma imagem, do que falam todos quando falam dessas coisas?

Talvez eu esteja resistindo a algo, como pensa Agamben ${ }^{12}$. O ato de criação é um ato de resistência, mas muito além de uma oposição a uma força externa. $\mathrm{O}$ ato criador libera uma potência interna ao próprio ato, assim como interno também é o ato de resistência. Quem possui uma potência pode colocá-la em ação ou não. $O$ arquiteto é considerado arquiteto mesmo enquanto não está construindo ou planejando, o médico é médico mesmo quando não está exercendo a medicina, assim como o pensamento existe com uma potência de pensar e não pensar, como uma tabuinha encerada sobre a qual não há nada escrito ainda, mas onde tudo pode ser escrito, como falava Aristóteles $^{13}$. Assim, há uma presença na ausência, daquilo que não está em ato (a potência). Ser poeta pode significar, então, estar à mercê de sua própria impotência (não como ausência de potência, mas como potênciade-não, potência de ser e de não ser, de fazer e de não fazer). Bartleby, o escriba que parou de escrever, é a figura do nada de onde vem toda a criação e, ao mesmo tempo, a reivindicação da absoluta potência. O seu "preferiria não" significa que não é que ele não queira copiar ou que queira não deixar o escritório, somente preferiria não o fazer. Isso destrói qualquer expectativa de construir uma relação entre poder e querer. Essa contingência (poder ser ou não) não se trata das rasuras ou variações dos manuscritos, mas daquele leve tremor na imobilidade da forma. Agamben se refere a Dante ${ }^{14}$, que resumiu em verso o caráter anfíbio da criação poética: "O artista / a quem, no hábito d'arte, treme a mão”. Todo artista está sujeito a desvios, relutâncias, a vacilações, uma resistência inerente a cada ato artístico. "O que treme e quase dança na forma é a potência" ${ }^{15}$, que não precede a obra, mas a acompanha, fazendo-a viver e abrindo possibilidades.

A metáfora do processo criativo elaborada por Felisberto Hernández em "Explicação falsa dos meus contos"16 exemplifica essa última ideia, que é mais interessante: não se trata só de pensar o ato criativo como a tensão de duas forças, e a obra como o resultado da liberação de uma delas, enquanto a outra fica "no escuro". Seria mais preciso pensar na tensão intrínseca à própria força do fazer, a tensão entre uma vontade e uma ausência de controle. Hernández se relaciona com seus contos como com uma semente que cresce e consigo mesmo como com um jardineiro-observador. Aquilo que o jardineiro observa é uma dimensão "misteriosa", constitutiva da semente, que ele conhece no seu desdobramento. Diferente de Levrero, ele não associa essa dimensão com o inconsciente, mas com a intervenção consciente do artista: "apesar da vigilância constante e rigorosa da

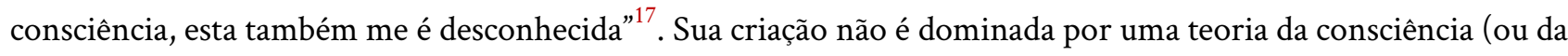

\footnotetext{
${ }^{12}$ AgAmBEN, op. cit., p. 59.

${ }^{13}$ Cf. livros Metafisica e De anima, de Aristóteles, citado por AGAMBEN, Giorgio. Bartleby: escrita da potência. Trad. Manuel Rodrigues e Pedro A. H. Paixão. Lisboa: Editora Assírio \& Alvim, 2007.

${ }^{14}$ AlighIERI, D. Divina comédia: Paraíso, canto XIII, versos 77-78. Citado por AGAMBEN, Giorgio. O fogo e o relato: ensaios sobre criação, escrita, arte e livros. Trad. Andrea Santurbano e Patricia Peterle. São Paulo: Boitempo, 2018.

${ }^{15}$ Ibidem, p. 71.

${ }^{16}$ HernÁndeZ, F. Explicação falsa dos meus contos. In: HeRnÁNDEZ, Felisberto. O cavalo perdido e outras histórias. São Paulo: Cosac Naify, 2004, p. 211-212.

${ }^{17}$ Ibidem, p. 211.
} 
obra) estabelecida a priori. Ele ronda a semente que aparece "num canto de si mesmo" e espera por um tempo, até que ela germine. Depois, ele deve cuidar que não ocupe espaço demais e que não se guie por pretensões como ser bela, intensa, ou ter determinada grandeza. O jardineiro a ajuda "para que seja (...) uma planta dona de si mesma, terá a poesia natural, desconhecida para si própria". Por isso, porque o observador se limita a ajudá-la a ser com toques delicados, "ela não conhecerá suas próprias leis, embora as tenha no mais fundo e a consciência não as possa alcançar. Não saberá o grau e a maneira como a consciência intervirá, mas em última instância imporá sua vontade. E ensinará a consciência a ser desinteressada" ${ }^{\text {"18 }}$.

A dobra é um conceito que Deleuze ${ }^{19}$ retira de Leibniz, que por sua vez retira do barroco. A dobra corresponde a um grau de instabilidade que o barroco expressa, pois o próprio barroco é uma arte em crise, onde o ser humano é louco e impregnado de incerteza sobre sua própria vida. E assim como existem dobras gregas, góticas e românicas, a dobra barroca possui a particularidade de ir até o infinito. O barroco, antes de tudo, é um traço que vai ao infinito. Parece que sempre existe uma dobra na dobra, como também uma caverna na caverna, uma coisa dentro da coisa. A dobra que vejo dentro da criação é a possibilidade de desdobrar aquilo que foi descartado, num constante exercício de reelaboração. Paisagens se tornaram cenários, meses passaram em minutos e às coisas atribuí sentimentos estranhos, igualmente fraturados, fracassados. Questionei a unidade de sentido de textos e imagens, uma vez que passei a entendê-los como membros de um mesmo discurso. Escrevo aquilo que escapa, aquilo que se esconde, aquilo que a dobra guarda.

A arte não é uma tarefa nem simplesmente uma obra, mas indica, nas palavras de Agamben, "a dimensão na qual as operações linguísticas e corpóreas, materiais e imateriais, biológicas e sociais são desativadas e contempladas como tais", numa espécie de "poética da inoperosidade" ${ }^{20}$. E, nesse plano, de deixar inoperantes todas as obras humanas, está a própria poesia, como diz Espinosa: "O que é, de fato, poesia se não uma operação na linguagem que desativa e torna inoperantes funções comunicativas e informativas desta, abrindo-se para um possível novo uso? ${ }^{21 "}$. A poesia desautomatiza as funções utilitárias da língua e repousa em si mesma, contempla sua potência de dizer, eis então a função poética da linguagem. Desse modo, escrever é mesmo mergulhar nas margens. As palavras se tornam abismo, mensageiras do absoluto no rastro de um não que persiste, essa potência de ser que resiste ao desejo, e, por isso, contempla. É atirar-se às margens do real para nele penetrar.

Procuro recriar as imagens pela experiência do desdobramento da linguagem. A escrita de cada texto é guiada por um movimento "sinestésico" entre as palavras, ou entre as palavras e a imagem que elas vão "revelando" no papel. Uma imagem (e não mais a imagem) vai se realizando no próprio ato da escrita. Tento deixar-me levar pelo percurso traçado na relação entre palavra, escrita e memória, não me preocupo mais pela "mimese" da suposta imagem "original" (aliás, inexistente). Isso exige um exercício de equilíbrio entre guiar e soltar, uma consciência desinteressada.

Quando mutilo um corpo em estado de ficção, permito que os elementos do texto se relacionem de outra maneira. Quebro um pescoço humano para ver de qual tronco brota a árvore que espero. Faz parte de uma expressão que me interessa trabalhar com a consciência da falha. Existe uma imposição em amarrar toda a

\footnotetext{
${ }^{18}$ Ibidem, p. 212.

${ }^{19}$ DeleuZe, G. A Dobra: Leibniz e o Barroco. Campinas, SP: Papirus, 2007.

${ }^{20}$ AGAMBEN, op. cit., p. 80.

${ }^{21}$ Ibidem.
} 
compreensão em um mesmo lugar e, claro, isso não existe. Cada parte carrega seu propósito e o propósito é a própria busca.

É preciso perceber o movimento e itinerário criativo, e entender que uma obra consiste não em sua forma definitiva, mas em uma cadeia infinita de interações de ideias trabalhadas em diferentes fases, isto é, em uma série infinita de aproximações para atingi-la, um fio que se desenrola numa multiplicidade de sentidos e relações. Para o crítico genético, segundo Tadié ${ }^{22}$, seria a poética dos rascunhos, a estética do movimento criador, a convivência de mundos possíveis. O artista levanta hipóteses, testa, com muitas possibilidades da obra habitando o mesmo teto. É a estética da continuidade, que dialoga com a estética do objeto estático, guardada pela obra de arte.

Na sua tentativa de escrever à maneira contínua e caótica da vida, Saramago ${ }^{23}$ diz que precisa "ouvir" a voz que fala internamente. Cristina Campo ${ }^{24}$ também cultiva o ouvido, mas ela considera a capacidade de ouvir como um "sentido sobrenatural" que conecta o indivíduo com seu próprio destino. Diferente de Saramago, para ela o sentido interno do ouvido, que pratica na escrita, se relaciona com a busca de uma ordem interna (não uma mimese). Oates ${ }^{25}$ e Levrero ${ }^{26}$ precisam "ver" com a maior nitidez possível aquilo que já está em seu inconsciente ou na sua memória. No processo de escrita, a leitura intervém de forma ativa, pelo menos de três maneiras. Como a presença fantasmagórica daquilo que o escritor ou escritora já leu ou viveu e que revive na contemplação (por meio dos sentidos) ou no gesto automático da imitação, às vezes sem ter sido convidada. Como instância crítica, de resistência ao impulso: aquele leitor invisível para quem se escreve e a quem se tenta agradar, mais responsável pelo não dito do que pelo dito. E depois da escrita, como aquilo que, de diversas formas, pode habitar a obra e permitir sua continuidade: a leitura dos outros.

Quebro ideias, uma a uma, para que caibam dentro de mim. Por pensar que não tinha fôlego para desenvolvê-las, abandonei, uma a uma, fora de mim. Como seriam se essas ideias estivessem vivas, em movimento, e não presas dentro de um catálogo de logo-mais, de depois-a-gente-vê, de quem-sabe-maistarde? E se essas ideias fossem livres, com a minha permissão de existência? Se tudo o que escondo revela a parte que sobra: é com ela que trabalho. O que resta de mim, um pedaço daquilo que não sei dizer. É nisso que me atenho. Só sei dizer o que não quero, o que não preciso e aquilo que não faço de jeito nenhum. O resto, eu bem que topo. Quando não faço, já estou fazendo. Não tenho tanta escolha quanto pensei. A rota de fuga é limitada. A escrita é um falso exercício de liberdade.

Atenta à folha em branco à minha frente, nem percebi quando chegou o inverno. O declínio foi gradual, com a queda nas temperaturas noturnas, os primeiros minuanos, as manhãs com névoa e a umidade contínua. O sol já nem aquecia tanto, apesar de que mal o visse através da cortina. Os olhos fixos buscam respostas, esperam que ecoem as vozes de algum lugar do fundo da página. A poesia deve ser mesmo o que diz Borges ${ }^{27}$ :

\footnotetext{
${ }^{22}$ TADIÉ, J. A crítica literária no século XX. Rio de Janeiro: Bertrand Brasil, 1992.

${ }^{23}$ SARAMAGO, J. Jornal do Brasil, Rio de Janeiro, 1 de novembro de 2008 [Entrevista de Bolívar Torres].

${ }^{24}$ CiRlot, V. El oído interior. Acerca del encuentro de Cristina Campo, María Zambrano y Marius Schneider. Acta poética. v. 35, n. 2, 2014, p. 169-186. Disponível em: https://www.sciencedirect.com/science/article/pii/S0185308214724241. Acesso em: 25 mar. 2021.

${ }^{25}$ OATES, op. cit., p. 35.

${ }^{26}$ LEVRERO, op. cit.

${ }^{27}$ Borges, J.L. Esse oficio do verso. Trad. José Marcos Macedo. São Paulo: Companhia das Letras, 2000, p. 11.
} 
ela está logo ali, à espreita, pode saltar sobre nós a qualquer momento. Mas as temperaturas diminuem ainda mais com a chuva que agora se avoluma no som das gotas no teto.

No seu Diário Volúvel ${ }^{28}$, Enrique Vila-Matas conta que quando ele escreve em casa se lembra dos dias em que era muito jovem e começou a escrever naquela mesma mesa de sempre. Para ele, escrever era afastar-se, deter-se, demorar-se, resistir-se à carreira mortal, à frenética velocidade geral da vida. Nesse aspecto eu sinto una hermandad com Vila-Matas: quando penso nos motivos e modos da escrita me vejo deitada naquela mesma cama de sempre, escrevendo um dos meus diários. Na minha rotina do diário há uma convicção sobre o saber do corpo. É a mão que guia, que unifica, que desenrola e alivia, chegando a beirar a experiência do vazio. O organismo asmático de Proust; o corpo convalescente de Onetti; a bipolaridade de Virginia Woolf; a epilepsia de Machado de Assis, que Silviano Santiago associa com certas brechas "convulsivas" na forma de sua literatura, são alguns exemplos da presença do organismo na escrita. A consciência disso me levou a abraçar, também na escrita, minha tendência natural e marcada às polaridades, a união do auto rreflexivo e confessional - mais íntimo -, com o abstrato e teórico - mais distante; uma tendência natural ao episódico, aliada a uma preocupação com o cíclico, com o fluxo e refluxo da emoção e do pensamento.

Engana-se quem pensa que o diário de criação é menos íntimo por manifestar aspirações sobre trabalho. Para Bakhtin $^{29}$, "o diário íntimo é impregnado de uma profunda confiança no destinatário, em sua simpatia, na sensibilidade e na boa vontade da sua compreensão responsiva. Nesse clima de profunda confiança, o falante abre as suas profundezas interiores". É pelo ofício que revelamos quem somos, o que desejamos e o que nos impede de escrever. Em nenhum outro lugar, me sinto tão apta para confessar que não sei, não quero, não gosto, não consigo. Talvez mapear aquilo que não fazemos seja um bom exercício para entender sobre quem realmente somos. $\mathrm{O}$ ato de abandonar uma ideia pode ter múltiplos significados. Lembro de Bourgeois que, mesmo sem expor seu trabalho, também não conseguia destruí-lo. Colecionar uma série de ideias como potência de não criação é um motivo para que eu possa desdobrar um diário pessoal em um catálogo para ampliar a noção de que as ideias se desenvolvem a partir de algum lugar e podem avançar ou recuar. É preciso estar atenta ao movimento que ocorre dentro da escrita. Maior que a ânsia pela criação deve ser o poder da observação.

Sentada à mesa, o calor aumenta, as mãos suam, a boca seca. Melhor esperar um pouco mais. Szymborska ${ }^{30}$ tinha razão, escrever é um filme monótono. Nas gavetas, guardadas à chave, ficam os objetos, rascunhos, toda a intimidade e os segredos de palavras com cheiro de naftalina, esquecidas em um tempo qualquer, à espera. É como se já tivessem se escoado todas as ideias e a capacidade de raciocínio vai se esgotando. A cada novo texto, é uma nova luta. Nas leituras, grandes poetas. Tudo o que você queria dizer, de alguma maneira, já foi dito. As marcações coloridas e os post-its vão se acumulando no meio dos livros. (Ei, não queira ser aquelas páginas! É preciso perceber ali outra essência, outro tempo. Compreenda por que seus poetas preferidos são imortais!). Os diários vão se acumulando, misturam desenhos, rascunhos e um punhado de sentimentos ocultos que se fundem em frases que só você entende, só ainda não percebe muito bem o que fazer com isso.

\footnotetext{
${ }^{28}$ Vila-MATAS, E. Diário volúvel. Trad. Jorge Fallorca. Lisboa: Teorema, 2010.

${ }^{29}$ BAKHTIN, M. Estética da criação verbal. São Paulo: Martins Fontes, 2003, p. 304.

30 SZYMBORSKA, W. O poeta e o mundo - discurso do Nobel 1996. In: SZYMBORSKA, Wisława. Um amor feliz. Seleção, tradução e prefácio de Regina Przybycien. São Paulo: Companhia das Letras, 2016, p. 323.
} 
"O tédio é o pássaro de sonho que choca os ovos da experiência" ${ }^{31}$. Para Benjamin, a perda da capacidade para assimilar e narrar histórias se relaciona com o desaparecimento progressivo das atividades associadas ao ócio que veio com a evolução das forças produtivas. A aceitação de que a força da resistência é constitutiva do ato criativo e da existência estética rasga o véu de raridade quase clínica que costuma envolver o processo de criação artística. Muitas das ações ou inações necessárias aos atos de escrever e de ser, de estar vivo, são tidas como inadequadas ou doentes. Inadequadas aos olhos da sociedade disciplinar que pratica a captura do ser naquilo conhecido como sujeito, e obstaculiza a descoberta de "novas possibilidades de uso" do corpo humano, na medida em que o ser fica cada vez mais afastado da persona, que está proibida de escutá-lo, vê-lo ou tocá-lo. Por isso também sinto una hermandad com Levrero quando ele diz que escrever não é se sentar para escrever, e comenta o menosprezo da inspiração, comum nos relatos de escritores profissionais, comprometidos com uma demanda de produtividade acelerada: "O imprescindível, não para escrever, mas para estar realmente vivo, é o tempo de ócio. Mediante o ócio é possível harmonizar-se com o próprio espírito, ou ao menos prestar-lhe algo da atenção que merece”32.

Os experimentos poéticos, diferentemente dos científicos, não concernem ao resultado de uma hipótese, à verificação ou à falsificação, mas questionam o próprio ser. "São experimentos sem verdade, porque neles não se trata da verdade", dizia Agamben ${ }^{33}$. Quem se aventura nesses experimentos não arrisca propriamente a verdade de seus enunciados, mas o seu próprio modo de existir, realizando no âmbito de sua história subjetiva uma mutação antropológica absolutamente decisiva. Essa outra classe de experimentos também procura responder a uma pergunta: em quais condições alguma coisa pode ser verificada e, ao mesmo tempo, não se verificar, sendo não apenas verdadeira, mas também falsa? Somente em uma experiência que se desconectou de qualquer relação com a verdade. Se ninguém pode pretender verificar a fórmula da escrita é porque o experimento sem verdade não remete ao ser ou não ser, mas ao seu ser em potência. E essa potência, a qualquer condição de verdade, segue um princípio básico - o mais firme de todos os princípios - o princípio de contradição.

A criação artística é marca da dinamicidade em um ambiente de flexibilidade, mobilidade e plasticidade. A não linearidade e a incerteza levam ao conceito de rede, às diversas relações possíveis e infinitas possibilidades de obras que vão se modificando ao longo do processo, em intensas conexões. $\mathrm{O}$ ato criativo é um complexo percurso com múltiplas transformações. É contínuo e simultâneo, renova-se a cada instante admitindo constantes progressões e regressões (talvez até mais regressões). Escrever é isso, colocar-se em movimento. A escrita é gesto, é ato, é performance. E pensar a criação como um processo implica deslocamento, continuidade (e descontinuidade) em um tempo plural e em um percurso com inúmeras rotas. Depois da viagem, como bem diz Szymborska $^{34}$, mesmo escrevendo incessantemente, a cada novo trabalho, o poeta sempre repetirá: "não sei”.

\footnotetext{
${ }^{31}$ BENJAMIN, W. O narrador. Considerações sobre a obra de Nikolai Leskov. In: BENJAMIN, Walter. Obras Escolhidas. Magia e técnica, arte e política: ensaios sobre literatura e história da cultura. São Paulo: Brasiliense, 1985, p. 204.

${ }^{32}$ LEVRERO, op cit, p.132.

${ }^{33}$ AgAmBEn, G. Bartleby ou da contingência. São Paulo: Autêntica, 2015, p. 119.

${ }^{34}$ SZYMBORSKA, op. cit., p. 325.
} 


\section{Referências Bibliográficas}

AgAMBEN, Giorgio. O fogo e o relato. Ensaios sobre criação, escrita, arte e livros. Tradução de Andrea Santurbano e Patricia Peterle. São Paulo: Boitempo Editorial, 2018.

AGAMBEN, Giorgio. Bartleby ou da contingência. São Paulo: Autêntica, 2015.

Agamben, Giorgio. Bartleby: escrita da potência. Trad. Manuel Rodrigues e Pedro A. H. Paixão. Lisboa: Editora Assírio \& Alvim, 2007.

BENJAmin, Walter. Passagens. São Paulo: Imprensa Oficial/Ed. UFMG, 2006.

BENJAMIN, Walter. O narrador. Considerações sobre a obra de Nikolai Leskov. In: Obras Escolhidas.

Magia e técnica, arte e politica: ensaios sobre literatura e história da cultura. São Paulo: Brasiliense, 1985, p. 197221

Borges, Jorge Luis. Esse oficio do verso. Trad. José Marcos Macedo. São Paulo: Companhia das Letras, 2000.

Cirlot, Victoria. El oído interior. Acerca del encuentro de Cristina Campo, María Zambrano y Marius Schneider. Acta poética. v. 35, n. 2, 2014, p. 169-186. Disponível em: https://www.sciencedirect.com/science/article/pii/S018530821472424. Acesso em: 25 mar. 2021.

COMPAGNON, Antoine. O trabalho da citação. Minas Gerais: UFMG, 2007.

DELEUZE, Gilles. A Dobra: Leibniz e o Barroco. Campinas, SP: Papirus, 2007.

Deleuze, Gilles. O ato de criação. Folha de S. Paulo, São Paulo, 27 jun. 1999. Trad. José Carlos Macedo. Disponível em: https://lapea.furg.br/images/stories/Oficina_de_video/o\%20ato\%20de\%20criao\%20\%20gilles\%20deleuze.pdf. Acesso em: 25 mar. 2021.

HERNÁNDEZ, Felisberto. Explicação falsa dos meus contos. In: O cavalo perdido e outras histórias. São Paulo: Cosac Naify, 2004, p. 211-212.

LEVRERO, Mario. Entrevista imaginária com Mario Levrero. In: Deixa comigo. Trad. Joca Reiners Terron. Rio de Janeiro: Rocco, 2013, p. 119-145.

OATES, Joyce Carol. Running and Writing. In: The Faith of a Writer: Life, Craft, Art. London:

PerfectBound, 2003, p. 29-36

SALLES, Cecília. Gesto inacabado: Processo de criação artística. São Paulo, Fapesp.

Editora: Annablume, 2008.

SANTIAGO, Silviano. Machado. São Paulo: Companhia das Letras, 2016.

SARAmago, José. Jornal do Brasil, Rio de Janeiro, 1 de novembro de 2008 [Entrevista de Bolívar Torres].

SZYMBORSKA, Wisława. O poeta e o mundo - discurso do Nobel 1996. In: Um amor feliz. Seleção, tradução e prefácio de Regina Przybycien. São Paulo: Companhia das Letras, 2016, p. 323-325.

TADIÉ, Jean-Yves. A crítica literária no século XX. Rio de Janeiro: Bertrand Brasil, 1992.

VIla-Matas, Enrique. Diário volúvel. Trad. Jorge Fallorca. Lisboa: Teorema, 2010.

Vila-MATAS, Enrique. Bartleby e companhia. Trad. Maria Carolina de Araújo e Josely Vianna Baptista. São Paulo: Cosac Naify, 2004. 